\title{
The Electrical Energy Modeling of the Modular Off-Grid PV System for Aquaculture Application in the EEC Region
}

\author{
Sukkhi Buakaew ${ }^{1}$, Prayut Jiamrittiwong ${ }^{1}$, and Nutdechatorn Puangngernmak ${ }^{1, *}$ \\ ${ }^{1}$ Faculty of Science, Energy and Environment, King Mongkut's University of Technology North Bangkok Rayong Campus \\ 19 Moo 11 Nong Lalok, Ban Khai, Rayong 21120
}

\begin{abstract}
Renewable energy as a solar photovoltaic system represents an essential role in improving and promoting energy sustainability in agricultural/aquaculture-related activities. The "Crab Bank" is the program on practicing the caught gravid females of Blue Swimming Crab (BSC) in supporting conditions, allowing them to spawn and then release the zoea and young crabs back to the sea where are in the Eastern Economic Corridor (EEC). Onward with the project, many scientific studies assess the BSC stocks condition, evaluate the fishing habitat, and other relevant issues as the energy used in a micro-indoor system as Recirculating Aquaculture Systems (RAS). The off-grid solar photovoltaic system is used in the system cause the installed location was near the seaside area. The system's large size was operating, including solar panels, inverter, charger, and batteries to maintain the AC motor pump, affecting much energy loss in the system. The off-grid solar system design for modular systems is represented in this paper to describe the new structure of the micro modular RAS that reduces cost and increases the solar system's efficiency in modular concepts comparing the traditional system. The new structure model represents the calculation result in the term of electrical energy and experiment to scale for replacement in the aquaculture area in Rayong or Jantaburi in the EEC region. This research is a cooperation between KMUTNB Rayong and the Provincial Energy Office Of Rayong.
\end{abstract}

Keyword. Photovoltaic system, Off-grid solar system, Recirculating Aquaculture System, Eastern Economic Corridor (EEC), Modular solar system.

\section{Introduction}

The Crab Bank is a sustainable crab conversation project first implemented in Pakklong, Pathew district, Chumphon province, Thailand, for a scheming conservative crab source [1-3]. This concept was a decent case project on practicing the caught gravid females of Blue Swimming Crab (BSC) in supporting conditions, allowing them to spawn and then releasing the zoea and young crabs back to the sea area the Eastern Economic Corridor (EEC).

Onward with the project, many scientific studies assess the BSC stocks condition, evaluate the fishing habitat, and other relevant issues as the energy using in a micro-indoor system as Recirculating Aquaculture Systems (RAS). The system was operating in a condition of feed seawater flow, oxygen feed rate that controls with electrical pump and air compressor. The source of energy supply is the off-grid solar photovoltaic system and installed location near the seaside area. However, renewable energy use promoting energy sustainability term. The efficiency should be a concern for the actual operation.

The traditional system was a simple off-grid design for an extensive system located on Chantaburi, helping for the research in area [4-5], as shown in Figure 1.
It was operating, including solar panels, inverter, charger, and batteries to maintain the $\mathrm{AC}$ electrical machine, affecting much energy loss in the system.

A high-efficiency inverter and an increasing number of solar panels and batteries required operating 24 hours a day with an electrical power of 565 Watt for all electrical machines in the extensive system.

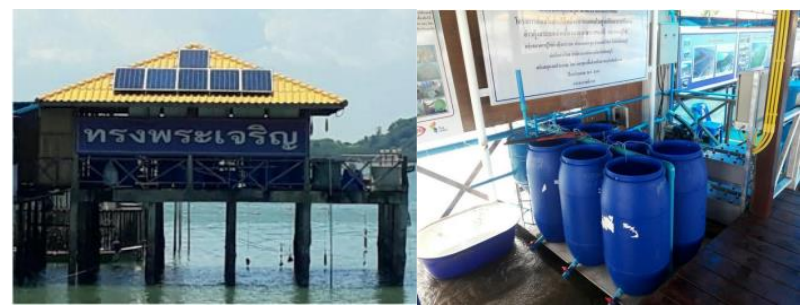

Fig. 1. The photo of the traditional system.

The traditional system includes an extensive system that is a high production scale for nursing the spawn and zoea. The support for a middle and large village uses high energy consumption and system installation and maintenance costs. The purpose system is the modular off-grid system that is compact, low energy consumption, and costs. The energy model using to design the module system with the relation of the

Corresponding author: nutdechatorn.p@ sciee.kmutnb.ac.th 
traditional system and operation parameters. The data of electrical measurement between an operation of the extensive and the module system using for developing the energy model.

\subsection{The PV off-grid energy model of the system}

\subsubsection{The traditional system}

The traditional system is an extensive system that includes two AC motors connecting to an air compressor (Supercharger) with redundancy mode operation and one AC motor pump for oxygen and water circulation of the micro-indoor system as RAS. The type of motor of the air compress and water pump is a single-phase $220 \mathrm{Vac}$ motor.

One unit of the extensive system can divide into three subsystems contains the total productivity for a maximum of $10.5 \mathrm{~kg}$ of spawn and used 3,780 lits of seawater. The diagram and photo of the extensive system and represented in Figures 2 and 3.



Fig. 2. The diagram of the extensive system.

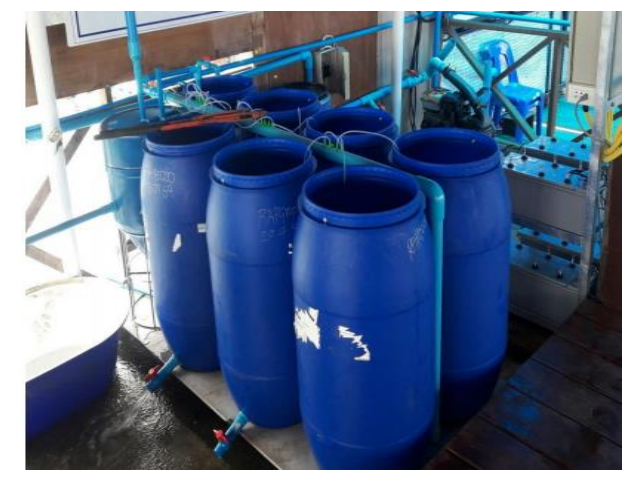

Fig. 3. The photo an one of three-part in the extensive system.

\subsubsection{The traditional off-grid PV system}

The traditional off-grid PV system consists of solar panels, a battery charger, and an inverter [6-8]. The solar panels and batteries design support the inverter and energy-souring to the system. The diagram of the PV system represents in Figure 4.

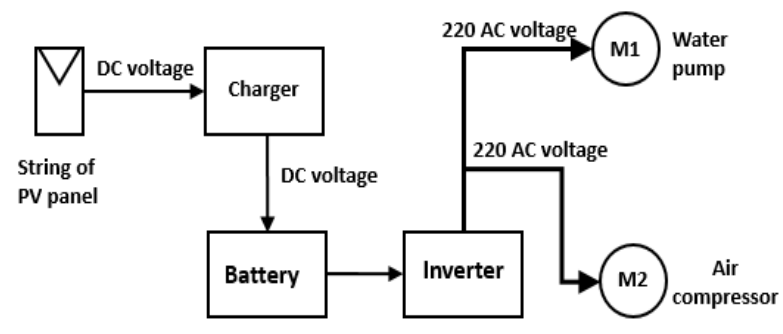

Fig. 4. The diagram of the PV system.

The electrical generate-time of solar panels depends on daylight time, around 5 hours/day. Therefore, the number and size of the panel and battery should be enough for energy-using in the application. The maintaining issue is another point of interest for design and cost-optimized.

\subsection{The PV off-grid modular concept}

\subsubsection{Concept of PV off-grid modular unit}

The concept of PV off-grid modular is proposed by the Provincial Energy Office Of Rayong for studies and optimize the efficiency and cost. Because of PV energy source for the traditional system was inefficient and needed more maintenance cost. For the small size of Crab bank, the extensive system is not appropriate and expensive in terms of production scale. Therefore, the modular concept using to the scale-down system into small production.

The modular unit consists of one dc motor pump and three motor air compressors. The diagram and photo of the modular concept represent in Figures 5 and 6.

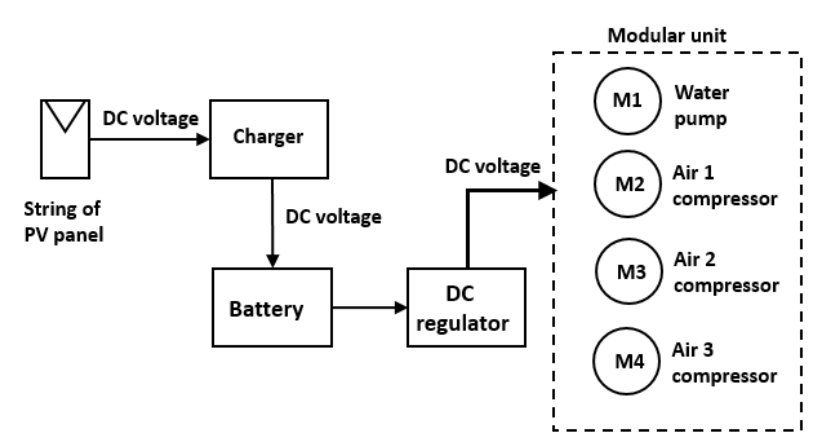

Fig. 5. The diagram of the modular system.

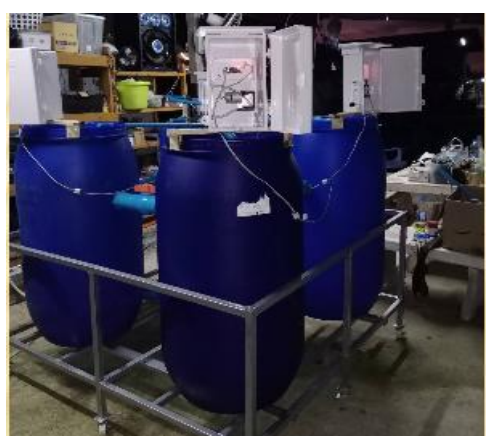

Fig. 6. The photo of the four modular system 


\subsubsection{The replacement in the traditional system}

The segment of the traditional system can be replaced by the proposed modular system, as shown in Figure 7, operated with three containers.

Each module has one water pump, and three air compressors operate independently with a single dc voltage source.

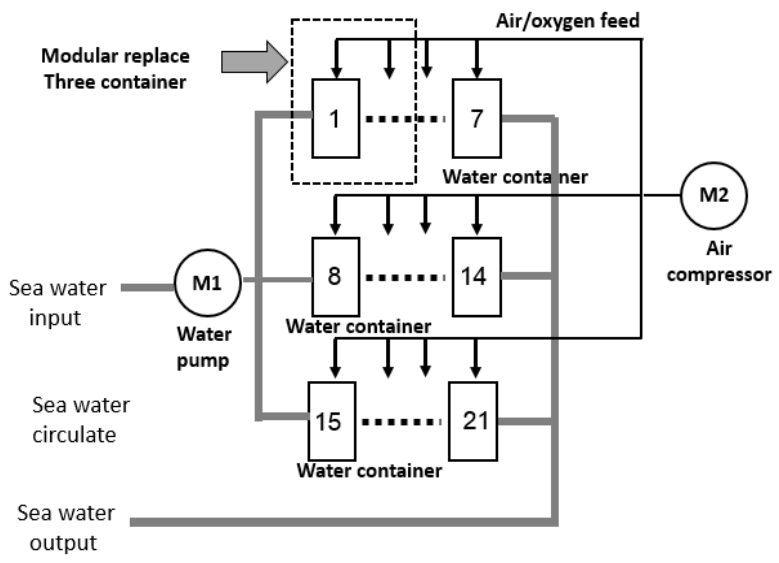

Fig. 7. The modular replacement in the traditional system

\section{Modeling the modular unit}

The energy model of the modular can be applying from the data of the extensive system. The description of electrical machines as datasheet or nameplate use to understand the relation of electrical energy used.

The working load of operation is used to create the reference load for optimizing and calculating the modular compared with the extensive. The electrical measurement processes are used for collecting the energy and re-calculate the model into the extensive.

\subsection{Methodology}

\subsubsection{Electrical energy of the extensive system}

First of all, the electrical instrument, power meter, and flow meter are used to collect the energy used in the extensive system.

The workload condition is setting with the onsite operation, and the instrument is collecting the data for one week of operation time. The condition of workload is measure with a flow meter as define in Table 1 . The electrical power use of the machine can represent in Table 2. The total power is 565 Watt.

The measurement result is the data for comparing and modeling the modular unit in the term of power.

Table 1. The condition workload of the extensive system.

\begin{tabular}{|c|c|c|}
\hline Parameter & value & unit \\
\hline $\begin{array}{c}\text { Water flow } \\
\text { (circuilation) }\end{array}$ & 4.5 & lit/minute \\
\hline $\begin{array}{c}\text { Air flow } \\
\text { (Oxygen feed) }\end{array}$ & 183.75 & lit/minute \\
\hline
\end{tabular}

Table 2. The measurement of electrical power of the AC machine.

\begin{tabular}{|c|c|c|}
\hline AC machine & value & unit \\
\hline $\begin{array}{c}\text { The motor of the } \\
\text { water pump }\end{array}$ & 135 & Watt \\
\hline $\begin{array}{c}\text { The motor of the air } \\
\text { compressor }\end{array}$ & 430 & Watt \\
\hline
\end{tabular}

\subsubsection{Electrical energy of the modular unit}

Similar to the extensive measurement process, the workload condition set up and fractions and scaling to the small and electrical instruments are used to collect the energy data. The DC machine (motor and air compressor) is used to apply the water flow and oxygen feed system. The working load condition defines in Table 3, and the electrical power represents in Table 4 .

Table 3. The condition workload of the modular unit

\begin{tabular}{|c|c|c|}
\hline Parameter & value & unit \\
\hline $\begin{array}{c}\text { Water flow } \\
\text { (circuilation) }\end{array}$ & 1.5 & lit/minute \\
\hline $\begin{array}{c}\text { Airflow } \\
\text { (Oxygen feed) }\end{array}$ & 26.25 & lit/minute \\
\hline
\end{tabular}

Table 4. The measurement of electrical power of DC machine.

\begin{tabular}{|c|c|c|}
\hline DC machine & value & unit \\
\hline $\begin{array}{c}\text { A dc motor of water } \\
\text { pump }\end{array}$ & 4 & Watt \\
\hline $\begin{array}{c}\text { A dc motors of air } \\
\text { compressor }\end{array}$ & 8 & Watt \\
\hline
\end{tabular}

\subsection{Electrical power and energy modeling}

Electrical power and energy relation between the extensive and the modular represented with equations (1) and (2).

The factor of energy is the operation time and power of the machine. The difference between both systems is the number and type of electrical machines that affect the energy consumption.

$$
\begin{gathered}
\mathrm{E}_{\text {system }}=\mathrm{P}_{\text {total }} \times \mathrm{t}_{\text {operation }} \\
\mathrm{P}_{\text {total }}=\sum \text { Power of electrical machine }
\end{gathered}
$$

where

$$
\begin{array}{ll}
\mathrm{E}_{\text {system }} & : \text { energy used in the system (W-hour) } \\
\mathrm{P}_{\text {total }} & : \text { total power of all machine in system }(\mathrm{W}) \\
\mathrm{t}_{\text {opearation }} & : \text { operation time of system (hour) }
\end{array}
$$




\section{The electrical energy modeling of the modular unit}

The modular unit's electrical power and energy models are written by equations (3) and (4). One of the modular systems consists of components are a dc pump and three dc compressors units.

$$
\begin{aligned}
\text { Power }_{\text {modular }} & =\text { Power }_{\mathrm{DC} \text { Pump }}+\sum \text { Power }_{\mathrm{DC} \text { Comp }} \\
\mathrm{E}_{\text {modular }} & =\text { Power }_{\text {modular }} \times \mathrm{t}_{\text {operation }}
\end{aligned}
$$

where

Power $_{\text {modular }}$ : power of the modular used (W)

Power $_{\text {DC Pump : }}$ power of dc pump unit (W)

Power $_{\text {DC Comp : }}$ power of dc compressor unit (W)

$\mathrm{E}_{\text {system }} \quad$ : energy used in the system (W-hour)

The relation of scale production between the modular system and the extensive system can be represented by equation (5) with the production factor $(\mathrm{k})$ is $14.3 \%$ that calculate from the total productivity for a maximum of the modular $(1.5 \mathrm{~kg})$ and the extensive $(10.5 \mathrm{~kg})$.

$$
\mathrm{Y}_{\text {modular }}=\mathrm{k} \times \mathrm{Y}_{\text {extensive }}
$$

where

$$
\begin{array}{ll}
\mathrm{Y}_{\text {modular }} & : \text { weight of product from the modular }(\mathrm{kg}) \\
\mathrm{Y}_{\text {extensive }} & : \text { weight of product from the extensive }(\mathrm{kg}) \\
\mathrm{k} & : \text { production factor }
\end{array}
$$

This model is used to optimize the system when replacing the extensive system with the modular system. Although the proposed model is only an electrical machine, it is to simplest to optimize the modular system.

\section{Result and conclusion}

The calculation power from proposing a modular model with one motor pump and three compressors is 28 Watt. The factor of production weight the modular to the extensive is $14.3 \%$, the recalculation of electrical power used in $100 \%$ is 195.80 Watt. The differential power between the extensive and the modular at same weight production is $565-195.80=374.2 \mathrm{Watt}$. Therefore, the power and energy used will reduce to $65.35 \%$.

However, the proposed modular contains $1.5 \mathrm{~kg}$ per three containers, affect the power reduced to 374.2 Watt. The trend of power used and production factor is represented by table 5 and figure 8 .

Table 5. The power uesd of modular varied with number of compressors and container.

\begin{tabular}{|c|c|c|}
\hline $\begin{array}{c}\text { No. of compressers and } \\
\text { containners }\end{array}$ & $\begin{array}{c}\text { Power used of } \\
\text { modular (W) }\end{array}$ & $\begin{array}{c}\text { Production } \\
\text { factor (\%) }\end{array}$ \\
\hline 3 & 28 & 14.3 \\
\hline 4 & 36 & 19.0 \\
\hline 5 & 44 & 23.8 \\
\hline 6 & 52 & 28.6 \\
\hline 7 & 60 & 33.33 \\
\hline
\end{tabular}

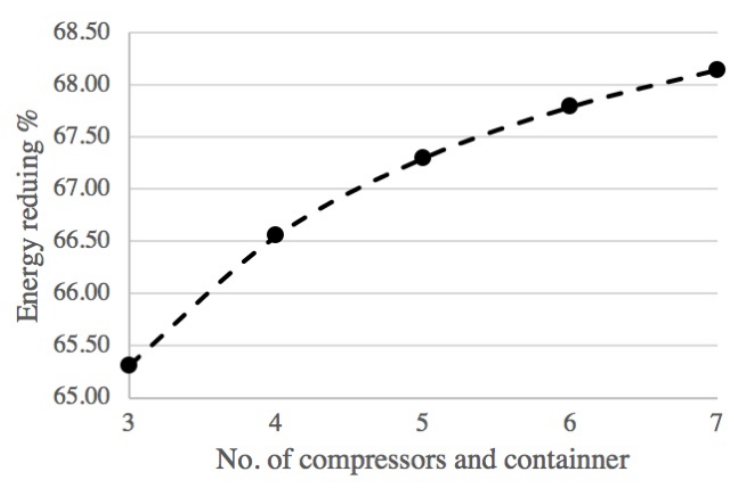

Fig. 8. The relationship between numbers of compresser/container and the percent of enegy reduction.

\section{References}

1. W. Arkronrat, V. Oniam, N. Hengcharoen, Crab bank implementation: Case study of the blue swimming crab bank in Prachuap Khiri Khan province, Thailand, Kasetsart University Fisheries Research Bulletin (Thailand), 37, 1 (2013) : 30-39

2. P. Suanrattanachai, T. Suppanirun, S. Etoh, V. Sulit, The Role of Crab Bank System in Securing Fisheries Livelihood and Resources Conservation and Management, Southeast Asian Fisheries Development Center, 7 , 1 (2009): 24-30

3. D. Thiammueang, R. Chuenpagdee, K. Juntarashote, The "Crab Bank" Project: Lessons from the Voluntary Fishery Conservation Initiative in Phetchaburi Province, Thailand, Kasetsart J. (Natural Sciences.) 46 (2012): 427-439

4. C. Kunsook, N. Gajaseni, N. Paphavasit, The Feeding Ecology of the Blue Swimming Crab, Portunus pelagicus (Linnaeus, 1758), at Kung Krabaen Bay, Chanthaburi Province, Thailand, Tropical Life Sciences Research, 25 (2014): 13-27

5. C. Kunsook, N. Gajaseni, N. Paphavasit, A Stock Assessment of the Blue Swimming Crab Portunus pelagicus (Linnaeus, 1758) for Sustainable Management in Kung Krabaen Bay, Gulf of Thailand, Tropical Life Sciences Research, 25 (2014): 41-59

6. G.K. Singh, Solar power generation by PV (photovoltaic) technology: A review, Energy, 53 (2013): 1-13

7. A. Ajan, J. Nirmala, Performance Evaluation of OnGrid and Off-Grid Solar Photovoltaic Systems, International Journal Of Innovative Research In Electrical, Electronics, Instrumentation And Control Engineering, 3 (2015): 20-23

8. M.L. Edson, B.L. Carine, T. Raymond, Performance Parameters Of An Off-Grid Building Integrated Photovoltaic System In South Africa, 33rd European Photovoltaic Solar Energy Conference and Exhibition 